\title{
Plasma Hormonal Levels of Rams are Affected by Sexual Activity and Confinement in a Semen Collection Centre
}

\author{
Carlos Palacios ${ }^{1}$; Soledad Álvarez ${ }^{1}$; Jesus Martín-Gil ${ }^{2}$; Jose-Alfonso Abecia ${ }^{3 *}$ \\ ${ }^{1}$ Departamento Construcción y Agronomía, Facultad de Ciencias Agrarias y Ambientales. Filiberto \\ Villalobos, Salamanca, Spain. \\ ${ }^{2}$ Departamento. Ingeniería Agroforestal, Universidad de Valladolid, Avda. de Madrid 57, \\ Palencia, Spain \\ ${ }^{3}$ IUCA, Departamento Producción Animal y Ciencia de los Alimentos. Facultad de Veterinaria. \\ Miguel Servet 177, Zaragoza, Spain. \\ *alf@unizar.es
}

\begin{abstract}
Two experiments were carried out to determine the effect of sexual activity and confinement in a semen collection centers (SCC) on plasma hormonal concentrations of rams. In experiment 1, rams were introduced into the flocks (active, $n=29$ ) or not, remained stabled with no access to the ewes (inactive, $n=22$ ). In experiment 2, animals were either at commercial flocks $(n=89)$ or at a SCC $(n=62)$. Rams were divided into active $(n=65)$, and inactive $(n=86)$. Plasma progesterone concentrations were not affected by sexual activity, management or breed. Plasma testosterone $(P<0.001)$, progesterone $(P<0.05)$, estradiol $(P<0.05)$ and cortisol $(P=0.01)$ concentrations were significantly affected by sexual activity, and testosterone $(P<0.05)$ and progesterone $(P<0.05)$ also by breed. Plasma estradiol concentrations were significantly modified by activity $(P<0.001)$, management $(P<0.001)$ and breed $(P<0.05)$. Plasma cortisol levels were only affected by place $(P=0.001)$. Plasma hormonal levels under study were affected by sexual activity when rams are in the flock. The higher levels of plasma cortisol presented by rams allocated in the SCC could indicate some degree of stress, although the absence of correlation between semen quality and hormonal levels suggests that restrain does not affect semen characteristics.
\end{abstract}

Keywords: ram, hormones, stress, cortisol, testosterone

\section{INTRODUCTION}

Sexual activity in sheep is mainly driven by photoperiod and melatonin secretion [1] through seasonal changes of the hormonal control of the reproductive system. Although this seasonal variation is less marked in the male than in the female sheep, rams during the non-reproductive season present a reduction in testicular volume and diameter, semen quality and modification of their hormonal profiles [2-3]. During the breeding season, the regulation of gonadotropin secretion in the ram is controlled by androgens and estrogens. Testosterone concentrations have been associated with prolonged exposure to estrous females [4]. Moreover, this hormone, which is essential for the development and maintenance of sexual behavior, is converted to estradiol by cytochrome P450 aromatase within the central nervous system of rams. There is evidence that this metabolite of testosterone and not testosterone itself is responsible for maintenance of sexual behavior in rams [5].

Progesterone produced by the corpus luteum and the placenta is the most important hormone in pregnancy in the ewe, although little information on the role of progesterone on male sexual behavior is currently available. In recent years, studies have provided valuable insight of progesterone modulating male sexual function. In fact, progesterone affects spermatogenesis in the male, capacitation of the sperm, and testosterone biosynthesis. The role of progesterone as a modulator of male sexual function became better established during the last decade [6].

In spite of seasonal variations, when rams are allowed to mate with estrous ewes and achieve multiple ejaculations, elevations in serum levels of LH, testosterone, and sometimes FSH have been noted [7]. In male goats, mating and/or aggressive behavior associated with mating days had a profound effect 
on the hormones profile of the animals, except during periods when they were already seasonally elevated. Thus, sexual activity is one of the factors affecting hormonal profiles of rams.

Rams assigned to artificial insemination or SCC use to remain stabled in individual pens. It is known that confinement of sheep in pens and, especially, their isolation from other sheep can be stressful for a time. The immediate effects include changes in plasma cortisol levels and disrupted behavior [8]. In the female sheep, it has been demonstrated that stressors associated with management practices can block the ability of exogenous estrogen to induce estrous behavior in progesterone primed ewes [9], so that management-related stress can disrupt reproduction by blocking the expression of estrous behavior. Moreover, episodic secretion of LH was inhibited by the stress of initial confinement, but several days of habituation to the same daily periods of confinement minimized this inhibition and restored the episodic discharges of LH [10]. There are sex differences in the response to stress and in the influence of stress on reproduction which may be due to gonadal steroids but the nature of these differences and the role of the gonads are not understood.

Castellana and Churra are two Spanish sheep breeds located at Castilla y Leon (Northern Spain), with approximately 220.000 and 450.000 heads, respectively [11]. Both breeds are bred for milk and meat production. The Assaf is the main dairy sheep breed in Israel, created by crossbreeding of the East Friesian (5/8) with the Awassi (3/8) breed [12]. It was exported to other Mediterranean countries, and currently, more than 1.5 million Assaf ewes are used in milk production in Spain. Although there are no available data in the literature regarding its sexual seasonality, it has been reported that the Spanish Assaf ewes are more seasonal than other breeds (Merino or Lacaune) reared in Spain at the same latitude [13].

It has been postulated [14] that elucidating hormonal changes in rams properly classified by sexual performance is important for understanding the biological basis of differences in breeding efficiency between rams. Thus, the objective of this work was to determine the effect of sexual activity (mating vs. sexual rest) and the confinement in a SCC on plasma hormonal concentrations (progesterone, estradiol, testosterone and cortisol) of rams of three breeds reared in Spain.

\section{Material ANd Methods}

All procedures were approved by the in-house Ethics Committee for Animal Experiments from the University of Zaragoza. The care and use of animals were performed accordingly with the Spanish Policy for Animal Protection RD1201/05, which meets the European Union Directive 86/609 on the protection of animals used for experimental and other scientific purposes.

\subsection{Experiment 1: Flocks.}

Fifty-one rams of the Castellana $(n=18)$, Churra $(n=25)$ and Assaf $(n=8)$ breeds, allocated in three Spanish commercial flocks of the same breed (Castellana, Cibanal, $41^{\circ} \mathrm{N}$; Churra, Fariza, $41^{\circ} \mathrm{N}$; Assaf, Pedrosa del Príncipe, $42^{\circ} \mathrm{N}$ ) were used. During the breeding season (November), rams were introduced into the flocks with the ewes (1 ram:20 ewes) and were mating for a period of a month (active rams, $n=29$ ). The rest of the rams remained stabled in a sheep house with no access to the ewes (inactive rams, $\mathrm{n}=22$ ). In the middle of the mating period, 15 days after the introduction of the rams into the flock, one blood sample was collected to analyze plasma testosterone, progesterone, estradiol and cortisol concentrations. Scrotal circumference was measured at the same time.

\subsection{Experiment 2: Flocks vs. SCC}

In mid-October, a total number of 151 rams of the Churra $(n=90)$ and Assaf $(n=61)$ breeds were used. Animals were allocated either at Spanish commercial flocks of the same breed (Churra, Arenillas de Riopisuerga, $42^{\circ} \mathrm{N}, \mathrm{n}=58$; Assaf, Olmedo, $41^{\circ} \mathrm{N}, \mathrm{n}=31$ ) or at a $\mathrm{SCC}$ which is responsible for the maintenance of the genetic selected rams of these breeds (OVIGEN, Zamora, $41^{\circ} \mathrm{N}$ ) (Churra, $\mathrm{n}=32$; Assaf, $n=30$ ). Rams were divided into two groups according their sexual activity at the moment of sampling, i.e. rams either mating ewes in the flocks (1 ram:20 ewes) or being semen sampled every two days at the SCC (active rams; Churra=39; Assaf, $n=26$ ), and rams either isolated in a sheep house from ewes in the flock, with no access to females, or not being semen sampled for at least one month at the SCC (inactive rams; Churra, $\mathrm{n}=50$; Assaf, $\mathrm{n}=36$ ).

One blood sample was collected to determine plasma progesterone, estradiol and cortisol concentrations. From those rams which were active and allocated in the SCC (Churra, n=16; Assaf, 
Plasma Hormonal Levels of Rams are Affected by Sexual Activity and Confinement in a Semen Collection Centre

$\mathrm{n}=15$ ), data from the semen sample obtained the same day than the blood samples were collected was recorded: ejaculate volume $(\mathrm{ml})$, concentration $(\mathrm{sperm} / \mathrm{ml})$ and motility (1-4).

\subsection{Hormonal determinations}

Concentration of progesterone $(\mathrm{ng} / \mathrm{ml})$, estradiol $(\mathrm{pg} / \mathrm{ml})$, and cortisol $(\mu \mathrm{g} / \mathrm{dl})$ were determined from plasma by chemiluminescent microparticle immunoassay (CMIA) (Architect kits, Abbot Diagnostic, USA). The concentration of testosterone $(\mathrm{ng} / \mathrm{ml})$ was determined by a microparticle enzyme immunoassay (MEIA) (AxSYM kit, Abbot Diagnostic, USA). The detection limits were $\leq 0.1 \mathrm{ng} / \mathrm{ml}$ (progesterone), $\leq 25 \mathrm{pg} / \mathrm{ml}$ (estradiol), $\leq 0.8 \mu \mathrm{g} / \mathrm{dl}$ (cortisol) and $\leq 0.2 \mathrm{ng} / \mathrm{ml}$ (testosterone). Intraassay variation coefficients were $12,14,8$ and $12 \%$, respectively.

\subsection{Statistical analysis}

Experiment 1 was based on a $2 \times 3$ factorial design in which sexual activity and breed were fixed effects, specified in a model that included sexual activity (active or inactive) and breed (Castellana, Churra or Assaf), and their interactions. Experiment 2 was based on a $2 \times 2 \times 2$ factorial design in which sexual activity, breed and management were fixed effects, specified in a model that included sexual activity (active or inactive), breed (Churra or Assaf) and management (flock or SCC), and their interactions. The probability level for statistical significance was set to $P<0.05$ and the results are expressed as mean \pm SEM.

\section{RESUlts}

\subsection{Experiment 1: flocks}

A significant effect of sexual activity was observed for the scrotal circumference measurements of the rams, active rams presenting a higher circumference $(P<0.05)$ than inactive rams (Table 1$)$. No breed differences were detected for this measurement (Table 2).

Table 1. Scrotal circumference $(\mathrm{cm})$, and plasma testosterone $(\mathrm{ng} / \mathrm{ml})$, progesterone $(\mathrm{ng} / \mathrm{ml})$, estradiol $(\mathrm{pg} / \mathrm{ml})$ and cortisol $(\mu \mathrm{g} / \mathrm{dl})$ concentrations of Castellana, Churra and Assaf rams, being active (mounting ewes) or inactive during the breeding season (mean \pm SEM)

Active Inactive

\begin{tabular}{lll}
\hline No. & \multicolumn{1}{c}{29} & \multicolumn{1}{c}{22} \\
Scrotal circumference & $30.93 \pm 0.62^{\mathrm{a}}$ & $28.82 \pm 0.74^{\mathrm{b}}$ \\
Testosterone & $3.22 \pm 0.70^{\mathrm{a}}$ & $3.08 \pm 0.84^{\mathrm{b}}$ \\
Progesterone & $0.43 \pm 0.02^{\mathrm{a}}$ & $0.40 \pm 0.04^{\mathrm{b}}$ \\
Estradiol & $46.31 \pm 5.18^{\mathrm{a}}$ & $27.36 \pm 2.63^{\mathrm{b}}$ \\
Cortisol & $1.60 \pm 0.13^{\mathrm{a}}$ & $0.89 \pm 0.14^{\mathrm{b}}$ \\
\hline
\end{tabular}

Progesterone and estradiol ( $a, b \quad P<0.05)$; Cortisol ( $a, b P<0.01)$; Testosterone $(a, b P<0.001)$

Table 2. Scrotal circumference $(\mathrm{cm})$, and plasma testosterone $(\mathrm{ng} / \mathrm{ml})$, progesterone $(\mathrm{ng} / \mathrm{ml})$, estradiol $(\mathrm{pg} / \mathrm{ml})$ and cortisol $(\mu \mathrm{g} / \mathrm{dl})$ concentrations of Castellana, Churra and Assaf rams during the breeding season (mean \pm SEM)

\begin{tabular}{lccc} 
& Castellana & Churra & Assaf \\
\hline No. & 18 & 25 & 8 \\
Scrotal circumference & $31.17 \pm 0.74$ & $29.08 \pm 0.67$ & $30.37 \pm 1.56$ \\
Testosterone & $1.30 \pm 0.40^{\mathrm{a}}$ & $3.52 \pm 0.83^{\mathrm{b}}$ & $6.22 \pm 1.84^{\mathrm{c}}$ \\
Progesterone & $0.34 \pm 0.02^{\mathrm{a}}$ & $0.77 \pm 0.40^{\mathrm{b}}$ & $0.40 \pm 0.04^{\mathrm{a}}$ \\
Estradiol & $42.28 \pm 6.98$ & $25.64 \pm 2.33$ & $34.38 \pm 2.68$ \\
Cortisol & $1.56 \pm 0.12$ & $0.94 \pm 0.11$ & $0.89 \pm 0.11$ \\
\hline
\end{tabular}

$a, b, c$ at least $P<0.05$ 
Plasma testosterone $(P<0.001)$, progesterone $(P<0.05)$, estradiol $(P<0.05)$ and cortisol $(P=0.01)$ concentrations were significantly affected by sexual activity (Table 1$)$, and testosterone $(P<0.05)$ and progesterone $(P<0.05)$ also by breed (Table 2$)$, with no interaction between both factors. Thus, active rams presented significantly higher hormonal concentrations than inactive rams. Low and nonsignificant correlation coefficients were observed between scrotal circumference and hormonal levels $(0.142,0.145,-0.007$ and 0.079 for testosterone, progesterone, estradiol and cortisol, respectively).

\subsection{Experiment 2: Flocks vs. SCC}

Plasma progesterone concentrations were not affected by either sexual activity (active: $0.35 \pm 0.03$; inactive: $0.64 \pm 0.36 \mathrm{ng} / \mathrm{ml}, P>0.05$ ), management (flock: $0.75 \pm 0.43$; SCC: $0.31 \pm 0.02 \mathrm{ng} / \mathrm{ml} ; P>0.05$ ) or breed (Churra: 0.65 \pm 0.38 ; Assaf: $0.35 \pm 0.19 \mathrm{ng} / \mathrm{ml} ; P>0.05$ ). However, plasma estradiol concentrations were significantly modified by activity (active: $25.44 \pm 2.16$; inactive: $17.68 \pm 0.81$ $\mathrm{pg} / \mathrm{ml}, P<0.001$ ), management (flock: 26.55 \pm 2.08 ; SCC: $16.61 \pm 0.73 \mathrm{pg} / \mathrm{ml} ; P<0.001$ ) and breed (Churra: $18.90 \pm 1.12$; Assaf: $23.87 \pm 2.02 \mathrm{pg} / \mathrm{ml} ; P<0.05$ ). Plasma cortisol levels were only affected by place (flock: $0.84 \pm 0.10$; SCC: $1.29 \pm 0.09 \mu \mathrm{g} / \mathrm{dl} ; P=0.001$ ), rams allocated in SCC presenting higher cortisol concentrations than rams in the flock. Neither sexual activity (active: 1.09 \pm 0.10 ; inactive: $1.08 \pm 0.10 \mu \mathrm{g} / \mathrm{dl} ; P>0.05$ ) nor breed (Churra: $1.00 \pm 0.09$; Assaf: $1.18 \pm 0.11 \mu \mathrm{g} / \mathrm{dl} ; P>0.05$ ) affected cortisol concentrations.

Significant differences between breeds were observed for semen volume (Churra: $0.90 \pm 0.04 \mathrm{ml}$; Assaf: $1.40 \pm 0.12 \mathrm{ml} ; P=0.001$ ) and total number of sperm (Churra: $2.70 \pm 0.30 \times 10^{9}$ cells; Assaf: $4.62 \pm 0.76 \times 10^{9}$ cells; $\left.P<0.05\right)$. Similar values within breeds were observed for sperm concentration (Churra: $2.94 \pm 0.24 \times 10^{9}$ cells $/ \mathrm{ml}$; Assaf: $3.21 \pm 0.35 \times 10^{9}$ cells $/ \mathrm{ml}$; NS) and basal motility (1-5) (Churra: 4.68 \pm 0.11 ; Assaf: 4.34 \pm 0.35 ).

Correlation coefficients between plasma hormonal values and seminal characteristics were low and non-significant, although a trend $(P<0.10)$ was observed for the correlation between plasma progesterone levels and sperm concentration and total sperm number (Table 3 ).

Table 3. Correlation matrixes between plasma hormonal concentrations and semen characteristics of Churra and Assaf rams.

\begin{tabular}{lllll} 
& Volume & Concentration $($ sperm $/ \mathrm{ml})$ & Total sperm number & Motility \\
\hline \multirow{2}{*}{ Estradiol } & 0.012 & 0.215 & 0.082 & 0.076 \\
& NS & NS & NS & NS \\
\multirow{2}{*}{ Progesterone } & 0.272 & 0.318 & 0.341 & -0.0 .60 \\
& NS & $P<0.1$ & $P<0.1$ & NS \\
Cortisol & 0.142 & 0.162 & 0.160 & -0.056 \\
& NS & NS & NS & NS \\
\hline
\end{tabular}

\section{DisCUSSION}

No breed differences were detected for scrotal circumference in experiment 1 . This is the opposite of that previously reported in the literature [15]. It is presumable that most of the ewes were already mated and less competence between rams was experimented. It has been reported [16] that both changes in live weight and scrotal circumference during the mating season showed a distinct pattern following sexual activity of the rams: a substantial decline during the period of peak sexual activity and recovery during the later stages of the mating period. The ram:ewe ratio and the paddock mating conditions can modify the variation of scrotal circumference throughout mating [16]. In spite of previous reports indicating that breed affects testis size [2,17], the absence of differences between rams for testis size observed in this experiment could also be attributable to the absence of differences of size and live weight between breeds that was reported in those references, not observables in the present work.

Although gonadotropins were not measured in this study breed differences in serum gonadotropin and testosterone have been observed only apparent during the short days [18], and breed differences in prolactin were noticeable only during long days when secretion of this hormone is enhanced. Breed 
differences in LH, FSH and testosterone secretion in rams during short days might were related to seasonality of mating and/or fecundity of breed types, since hormonal differences between rams of different breeds have been recorded only during the reproductive season and not during spring [4].

It has been reported that treatment of castrated rams with estradiol stimulates sexual behaviors $[18,19]$, but the treatment with the non-aromatizable dihydrotestosterone is ineffective [19,20,21]. This is in accordance with experiment 1 , where testosterone concentrations were not affected by sexual activity; sex drive in rams is not directly related to serum levels of testosterone [5]. There is no correlation between circulating levels of testosterone or other androgens and the level of sexual activity [22], nor are there differences in the concentrations of testosterone between high and low libido rams [14]. Inconsistent reports of testosterone secretion during sexual activity in the bull have been found, although it seems that the concentration of testosterone required to activate sexual behavior is lower than the threshold required for maintenance of ejaculatory mechanisms [20]. In the boar, testosterone levels are elevated during both sexual or aggressive behavior and this is correlated with an elevation in corticosteroids [23]. In this species, injected cortisol also elicits a rise in testosterone [23], and testosterone was unaffected by reproductive activities of bulls but increased in boars [24].

Plasma cortisol concentrations were significantly affected by sexual activity in experiment 1 ; this is in agreement with Borg et al. [24], who observed that cortisol levels were higher during periods of mating, and that mounting and intromission were associated with elevations in cortisol. It has also been observed that serving a cow or a sow is associated with stimulation of cortisol secretion in bulls and boars, respectively [25], concluding that the persistent and predictable cortisol response associated with mounting was brought about by the excitability associated with the desire to copulate. In our experiments, cortisol levels were affected by sexual activity only in the flocks (experiment 1 ), although in experiment 2, isolated rams from ewes increased their plasma cortisol concentrations in comparison with animals mounting in the flocks. It is likely that the restraint stress could stimulate a cortisol increase; thus, in bulls, stress-induced elevations in cortisol are associated with reduced testosterone secretion, and this effect may be due to direct suppression of Leydig cell steroidogenesis [26,27]. Something similar has been demonstrated in ewes, since stressors associated with management practices can block the ability of exogenous estrogen to induce estrous behavior in progesterone primed ewes [9], so that management-related stress can disrupt reproduction by blocking the expression of estrous behavior. Under anesthesia-induced stress, testosterone concentrations were greater and cortisol lower in female-oriented than in male-oriented and asexual rams [28], suggesting that increased stress responsiveness may be correlated with decreased libido.

References about the relationship between plasma steroidal hormonal levels and semen quality in the ram are scarce. Thus, testosterone levels have been significantly correlated with sperm motility and sperm concentration in Rahmani rams [29]. In experiment 2, only progesterone presented a trend to be correlated with some sperm characteristics. Progesterone has been shown to increase sperm functions crucial to fertilization such as hyperactivated motility, acrosome reaction, zona pellucida binding, and oolemma penetration in humans [30,31], although progesterone was not able to prevent cryodamage assessed by motility changes or membrane integrity in human spermatozoa of subfertile men [32].

\section{Conclusions}

In conclusion, in spite of breed differences, plasma hormonal levels under study were affected by sexual activity when rams were in the flock. The higher levels of plasma cortisol presented by rams allocated in the SCC could indicate some degree of stress, although the absence of correlation between semen quality indicators and plasma hormonal levels could suggest that restrain does not affect semen characteristics.

\section{ACKNOWLEDGMENTS}

The authors wish to thank the farmers involved in this work and the staff of OVIGEN for their help in the data records.

\section{REFERENCES}

[1]. Bittman E.L., Dempsey R.J. and Karsch F.J., Pineal melatonin secretion drives the reproductive response to day length in the ewe, Endocrinology,113, 2276-2283 (1983) 
[2]. Langford G.A., Shrestha J.N.B., Sanford L.M. and Marcus G.J., Reproductive hormone levels of early postpubertal ram lambs in relation to breed, adult testis size and semen quality, Small Rumin Res, 29, 225-231 (1988)

[3]. Lincoln G.A., Lincoln C.E. and Mcneilly A.S., Seasonal cycles in the blood plasma concentration of FSH, inhibin and testosterone and testicular size in rams of wild, feral and domesticated breeds of sheep, J Reprod Fertil, 88, 623-633 (1990)

[4]. Sanford L.M., Palmer W.M. and Howland B.E., Influence of age and breed on circulating LH, FSH and testosterone levels in the ram, Can J Anim Sci, 62, 767-776 (1982)

[5]. Perkins A. and Roselli C.E., The ram as a model for behavioral neuroendocrinology, Horm Behav, 52, 70-77 (2007)

[6]. Andersen M.L. and Tufik S., Does male sexual behavior require progesterone?, Brain Res Rev, 51, 136-143 (2006)

[7]. Yarney T.A. and Sanford L.M., Relationship between prepubertal reproductive-endocrine parameters and postpubertal testicular size and function of rams, Conference Proceeding, 10th Int. Congress on Animal Reproduction, Pp 178-180, (1984)

[8]. Fordham D.P., Al-Gahtani S., Durotoye L.A. and P.G. Rodway, Changes in plasma cortisol and beta-endorphin concentrations and behaviour in sheep subjected to a change of environment, Anim Prod, 52, 287-287 (1991)

[9]. K. Ehnert and G.P. Moberg, Disruption of estrous behavior in ewes by dexamethasone or management-related stress, Journal of Animal Science, 69, 2988-2994, 1991.

[10].D.D. Rasmussen and P.V. Malven, Effects of confinement stress on episodic secretion of LH in ovariectomized sheep, Neuroendocrinology, 36, 392-396, 1983.

[11]. Yanes J.E. and de la Fuente L.F., Situación censal de las razas Churra, Castellana y Ojalada en Castilla y León, Conference Proceeding, XXXVI Congress of the Sociedad Española de Ovinotecnia y Caprinotecnia, Pp 585-590, (2011)

[12]. Goot H., Development of Assaf, a synthetic breed of dairy sheep in Israel, Conference Proceeding, 37th Annual Meeting of the European Association of Animal Production, P 29, (1988)

[13].Palacios C., Martín S., Deletang F. and Martino A., Utilización en diciembre de los implantes de melatonina en diferentes razas ovinas, Conference Proceeding, XXVII Congress of the Sociedad Española de Ovinotecnia y Caprinotecnia, Pp 1088-1093, (2002)

[14].Perkins A., Fitzgerald J.A. and Price E.O., Luteinizing hormone and testosterone response of sexually active and inactive rams, J Anim Sci, 70, 2086-2093 (1992)

[15].Raadsma H.W. and Edey T.N., Mating performance of paddock mated rams. I. Changes in mating performance, ejaculate characteristics and testicular size during the joining period, Anim Reprod Sci, 8, 79-99 (1985)

[16]. Gizaw S.and Thwaites C.J., Changes in liveweight, body condition and scrotal circumference and their relationships with sexual activity and flock fertility in Ethiopian Horro rams over a 3 cycle joining period, J Agric Sci, 128, 117-121 (1997)

[17].Carr W.R. and Land R.B., Plasma luteinizing hormone levels and testis diameters of ram lambs of different breeds, J Reprod Fertil, 42, 325-333 (1975)

[18].D'Occhio M.J., Schanbacher B.D. and Kinder J.E., Profiles of luteinizing hormone, folliclestimulating hormone, testosterone and prolactin in rams of diverse breeds: effects of contrasting short (8L:16D) and long (16L:8D) photoperiods, Bio Reprod, 30, 1039-1054 (1984)

[19].Parrott R.F. and Baldwin B.A., Sexual and aggressive behaviour of castrated male sheep after injection of gonadal steroids and implantation of androgens in the hypothalamus: a preliminary study, Theriogenology, 21, 533-542 (1984)

[20].D'Occhio M.J. and Brooks D.E., Threshold of plasma testosterone required for normal mating activity in male sheep, Horm Behav, 16, 383-394 (1982)

[21].D'Occhio M.J., Galil K.A.A., Brooks D.E. and Setchell B.P., Differential effects of gonadectomy on sensitivity to testosterone of brain centres associated with gonadotrophin negative feedback and with mating behavior in rams, J Endocrin, 104, 69-75 (1985) 
[22]. Howles C.M., Webster G.M. and Haynes N.B., The effect of rearing under a long or short photoperiod on testis growth, plasma testosterone and prolactin concentrations and the development of sexual behaviour in rams, J Reprod Fertil, 60, 437-447 (1980)

[23].Liptrap R.M. and Raeside J.I., A relationship between plasma concentrations of testosterone and corticosteroids during sexual and aggressive behavior in the boar, J Endocrin, 76, 75-75 (1978)

[24].Borg K.E., Esbenshade K.L. and Johnson B.H., Effects of sexual experience, season and mating stimuli on endocrine concentrations in the adult ram, Horm Behav, 26, 87-109 (1992)

[25].Borg K.E., Esbenshade K.L. and Johnson B.H., Cortisol, growth hormone and testosterone concentrations during mating behavior in the bull and boar, J Anim Sci, 69, 3230-3240 (1991)

[26]. Welsh T.H. and Johnson B.H., Stress induced alterations in secretion of corticosteroids, progesterone, luteinizing hormone and testosterone in bulls, Endocrinology, 109, 185-190 (1981)

[27].Welsh T.H., Bambino T.H. and Hsueh A.J.W., Mechanism of glucocorticoid-induced suppression of testicular androgen biosynthesis in vitro, Bio Reprod, 27, 1138-1146 (1982)

[28].Roselli C.E., Stormshak F., Stellflug J.N. and Resko J.A., Relationship of serum testosterone concentrations to mate preferences in rams, Bio Reprod, 67, 263-268 (2002)

[29].Kishk W.H., Interrelationship between ram plasma testosterone level and some semen characteristics, Slovak J Anim Sci, 41, 67-71 (2008)

[30]. Sueldo C., Oehninger S., Subia E., Mahony M., Alexander N., Burkman L.J. and Acosta A.A., Effect of progesterone on human zona pellucida sperm binding and oocyte penetrating capacity, Fertili Steril, 60, 136-140 (1993)

[31]. Oehninger S., Sueldo C., Lanzendorf S., Mahony M., Burkman L.J., Alexander N.J. and Hodgen G.D., A sequential analysis of the effect of progesterone of specific sperm functions crucial to fertilization in vitro in infertile patients, Human Reprod, 9, 1322-1327 (1994)

[32].Duru N.K., Morshedi M., Schuffner A. and Oehninger S., Semen treatment with progesterone and/or acetyl-L-carnitine does not improve sperm motility or membrane damage after cryopreservation-thawing, Fertil Steril, 74, 715-720 (2000) 